\title{
Effects of Growth Hormone Treatment and Rehabilitation in Incomplete Chronic Traumatic Spinal Cord Injury: Insight from Proteome Analysis
}

\author{
Tatiana Martin-Rojas ${ }^{1}$, Tamara Sastre-Oliva ${ }^{1}$, Ana Esclarín-Ruz ${ }^{2}{ }^{\circledR}$, Felix Gil-Dones ${ }^{1,3}$, \\ Laura Mourino-Alvarez ${ }^{1}$ (D), Nerea Corbacho-Alonso ${ }^{1}$, Rafael Moreno-Luna ${ }^{1,4}$, \\ German Hernandez-Fernandez ${ }^{1}$, Juan Antonio Lopez ${ }^{5}$ (D), Antonio Oliviero ${ }^{6, *}$ and \\ María G. Barderas 1,* \\ 1 Department of Vascular Physiopathology, Hospital Nacional de Paraplejicos (HNP), SESCAM, \\ 45071 Toledo, Spain; tatiana_martin_rojas@hotmail.com (T.M.-R.); tsastre@sescam.jccm.es (T.S.-O.); \\ gildones@yahoo.es (F.G.-D.); lmourino@sescam.jccm.es (L.M.-A.); ncorbacho@sescam.jccm.es (N.C.-A.); \\ rmluna@sescam.jccm.es (R.M.-L.); ghernandezf@externas.sescam.jccm.es (G.H.-F.) \\ 2 Department of Physical Medicine and Rehabilitation, Hospital Nacional de Parapléjicos, SESCAM, \\ 45071 Toledo, Spain; anae@sescam.jccm.es \\ 3 Department of Genetic, Facultad de Ciencias Biológicas, UCM, 28040 Madrid, Spain \\ 4 Department of Neuroinflammation, Hospital Nacional de Paraplejicos (HNP), SESCAM, 45004 Toledo, Spain \\ $5 \quad$ Unidad de Proteomica CNIC, 28029 Madrid, Spain; jalopez@cnic.es \\ 6 FENNSI Group, Hospital Nacional de Parapléjicos, SESCAM, 45071 Toledo, Spain \\ * Correspondence: antonio.oliviero@hotmail.com (A.O.); megonzalezb@sescam.jccm.es (M.G.B.); \\ Fax: +34-925-247-745 (M.G.B.)
}

Received: 18 September 2020; Accepted: 19 October 2020; Published: 21 October 2020

\begin{abstract}
Despite promising advances in the medical management of spinal cord injury (SCI), there is still no available effective therapy to repair the neurological damage in patients who experience this life-transforming condition. Recently, we performed a phase II/III placebo-controlled randomized trial of safety and efficacy of growth hormone $(\mathrm{GH})$ treatment in incomplete chronic traumatic spinal cord injury. The main findings were that the combined treatment of GH plus rehabilitation treatment is feasible and safe, and that GH but not placebo slightly improves the SCI individual motor score. Moreover, we found that an intensive and long-lasting rehabilitation program per se increases the functional outcome of SCI individuals. To understand the possible mechanisms of the improvement due to GH treatment (motor score) and due to rehabilitation (functional outcome), we used a proteomic approach. Here, we used a multiple proteomic strategy to search for recovery biomarkers in blood plasma with the potential to predict response to somatropin treatment and to delayed intensive rehabilitation. Forty-six patients were recruited and followed for a minimum period of 1 year. Patients were classified into two groups based on their treatment: recombinant somatropin $(0.4 \mathrm{mg})$ or placebo. Both groups received rehabilitation treatment. Our strategy allowed us to perform one of the deepest plasma proteomic analyses thus far, which revealed two proteomic signatures with predictive value: (i) response to recombinant somatropin treatment and (ii) response to rehabilitation. The proteins implicated in these signatures are related to homeostasis, inflammation, and coagulation functions. These findings open novel possibilities to assess and therapeutically manage patients with SCI, which could have a positive impact on their clinical response.
\end{abstract}

Keywords: spinal cord injury; somatropin; therapy; proteomic 


\section{Introduction}

The annual incidence of traumatic spinal cord injury (SCI) in Spain is estimated at 1000 cases, with the vast majority caused by traffic accidents ( $48 \%)$, followed by falls $(21 \%)$ and sport injuries (14.6\%) [1]. In addition, there are also many other cases of non-traumatic SCI of other origins, such as tumors, infectious and vascular diseases, and multiple sclerosis, among others [2]. The most common medical classification to characterize SCI is the International Standards for Neurological Classification of Spinal Cord Injury (ISNCSCI) to classify subjects using the ASIA Impairment Scale (AIS) and the neurological level of SCI (the more caudal neurological level with normal neurological function). ISNCSCI categorizes injuries by severity into complete (patient without sacral preservation; defined as ASIA A), and incomplete (patients with sensorimotor sacral preservation) injury, which is further subdivided into different degrees of involvement (B, C, D and E) [2]. Presently, there is no treatment available for SCI once it is established, and rehabilitation is the only therapy for functional improvement. The life-changing consequences, along with the high social cost and the lack of treatment options make the study of SCI pathophysiology an important scientific and medical objective [3].

The incidence of traumatic SCI is higher in younger persons between 16 and 30 years (and more often in males), and the prevalence is higher in the 40-49 years age group, with chronic lesions of more than 15-20 years (www.christopherreeve.org). Patients with traumatic SCI can show an improvement in motor and sensory functions during the first year, but there is usually little progress after this period [4-6]. Accordingly, expert guidelines [6] consider that the clinical condition of patients is unlikely to change after 12-18 months without the aid of rehabilitation, and clinical trials should be performed from this time onwards $[5,6]$.

Growth hormone $(\mathrm{GH})$ is a polypeptide hormone secreted by the anterior pituitary gland that stimulates growth, cell reproduction, and cell regeneration in humans and other animals $[7,8]$. GH also stimulates the production of insulin growth factor-1 (IGF-1) and increases the concentration of glucose and free fatty acids [9-11]. GH is commonly used by physicians as a replacement therapy to treat children with hormone deficiency and growth retardation, and it is now manufactured by recombinant DNA technology-producing somatotropin that has an identical amino acid sequence to that of the isolated human pituitary hormone [12]. Maximum plasma concentrations of GH are reached two to six hours after injection. The effects of $\mathrm{GH}$ are focused on minimizing protein loss through oxidation and increasing body and muscle mass [13]. Furthermore, GH plays an important paracrine effect on the central nervous system [14], where thyroid-stimulating hormone (TSH) is also implicated in the normal development of the nervous system, too [14-18]. The role of GH in the adult nervous system is controversial, but it has been reported to exert neuroprotective and neuroreparative functions $[7,8]$. Accordingly, in the context of SCI, GH treatment combined with physical therapy might provide neuroprotection and prevent further loss of nerve tissue.

The last few years have witnessed substantial improvements in mass spectrometry (MS)-based proteomics techniques, including sample preparation, liquid chromatography MS hardware, and data analysis [19-22]. In the present study, we applied several proteomics strategies for the unbiased, non-targeted study of patients with chronic SCI treated with rehabilitation and with or without somatropin in an attempt to decode the role of rehabilitation and somatropin treatment in chronic SCI individuals. Furthermore, we try to identify recovery markers in blood plasma samples in these kinds of patients.

\section{Materials and Methods}

\subsection{Patient Recruitment and Study Design}

Patient selection and classification was carried out by Physical Medicine and Rehabilitation department of the Hospital Nacional de Parapléjicos (Toledo, Spain). Forty-six patients with chronic SCI classified by lesion level (C4 and T12) were followed for a minimum period of one year every 6 months at the Neurology and Rehabilitation Department. The study was conducted according to the 
recommendations of the Declaration of Helsinki and was approved by the local Ethics Committee. In all cases (The ethic approval code is: 70/2010), informed consent was requested from all subjects participating in the study.

After considering the inclusion and exclusion criteria (Table 3), patients were randomly divided into two groups (treatment and control). Randomization was achieved using a computer randomization program, and the records were held in the hospital Neurology Department (centralized randomization). A subgroup of the clinical trial also participates to this study. Overall, 23 patients received a daily dose of somatropin (recombinant somatropin-Genotonorm Miniquick ${ }^{\circledR}, 0.4 \mathrm{mg}$ ) over 364 days and also rehabilitation during the first six months. Twenty-three patients received placebo injection and rehabilitation following the same protocol (Figure 1). The proteomic study comprised two phases, a discovery phase and a validation phase. For the discovery phase, 26 patients with SCI were classified depending on pharmacological treatment: recombinant somatropin (group A) or placebo (group B). The discovery phase was followed by a verification phase, where we examined the proteins of interest in an independent cohort of patients $(n=20)$ with the objective of validating our findings in a different SCI population. All patients were matched by baseline characteristics and medication (Table 2).

Table 1. Inclusion and exclusion criteria.

\begin{tabular}{cc}
\hline Inclusion Criteria & Exclusion Criteria \\
\hline Age $<18$ or $>75$ years \\
Etiology: Non-traumatic spinal cord injury \\
Complete SCI (AIS A) \\
Incomplete SCI (AIS D or E) \\
Neurological level above C4 or below T12 \\
Time since injury $<18$ months \\
Age between 18 and 75 years & Intensive Care Unit stay for a period of $\geq 2$ months More than 3 urinary \\
Incomplete SCI (AIS B or C) & tract infections in the last year \\
Etiology: traumatic & Pneumonia in the 6 months prior to the study or severe \\
reurological level between C4 and T12 & respiratory failure \\
Time since injury $>18$ months & History of head trauma \\
& Severe psychiatric disorder \\
& History of heart disease, diabetes or hypertension \\
Concomitant neurological diseases \\
Regular use of substances of abuse \\
Severe kidney and/or liver failure. \\
\\
Impossibility to be included in an intensive rehabilitation program \\
Pregnancy or breast-feeding \\
History of malignancy \\
Impossibility to obtain informed consent \\
\hline
\end{tabular}

Table 2. Clinical characteristics of subjects with spinal cord injury (SCI) and with combined rehabilitation and somatropin treatment. (CI, confidence interval).

\begin{tabular}{|c|c|c|c|c|c|c|}
\hline Characteristics & Mean & GH Group & C I & Placebo Group & C I & $p$ \\
\hline $\begin{array}{c}\text { No of } \\
\text { subjects }\end{array}$ & & 23 & & 23 & & \\
\hline Sex (Male) & & $\mathrm{z}$ & & & & 0786 \\
\hline Male & 82.88 & & & & & \\
\hline Female & 17.12 & & & & & \\
\hline Age (y) & 35.00 & & & & & 0946 \\
\hline AIS grade & Only baseline & & & & & \\
\hline A & Not include & & & & & NA \\
\hline B & 55.48 & & & & & NA \\
\hline $\mathrm{C}$ & 44.42 & & & & & NA \\
\hline $\mathrm{D}$ & Not include & & & & & NA \\
\hline \multicolumn{7}{|l|}{ IGF-1 } \\
\hline Baseline & & 195.83 & 28.50 & 199.66 & 27.48 & 05567 \\
\hline \multicolumn{7}{|l|}{ Motor score } \\
\hline Baseline & & 44.44 & 6.99 & 36.38 & 6.95 & 0119 \\
\hline
\end{tabular}


For the proteomics analysis, $7 \mathrm{~mL}$ of blood was drawn into ethylenediaminetetraacetic acid (EDTA)-prepared collection tubes (Venoject, Terumo Europe, Leuven, Belgium). Samples were immediately taken to our laboratory (within $2 \mathrm{~h}$ ) to minimize sample degradation. Samples were centrifuged at $3500 \times \mathrm{g}$ for $10 \mathrm{~min}$ at $4{ }^{\circ} \mathrm{C}$, and the resulting plasma was aliquoted in batches of $500 \mu \mathrm{L}$ and stored at $-80{ }^{\circ} \mathrm{C}$ until proteomic analysis. Plasma samples were collected at baseline and at 6 months. Patients were followed up for 1 year after the start of the study.

\subsection{Motor Score Evolution and Measurement of Insulin-Like Growth Factor-1 Plasma Levels}

Motor score evaluation was performed for each patient at baseline and at 6 months. Measurement of IGF-1 was performed at the hospital Clinical Analysis Laboratory using commercial ELISA kits (Thermo Fisher Scientific, Watham, MA, USA).

\subsection{Proteomics Overview}

The experimental strategy consisted of the following: (1) immunodepletion of the 14 more abundant plasma proteins [23]; (2) a discovery phase using two different, complementary, and robust proteomics techniques: two-dimensional fluorescence difference gel electrophoresis (2D-DIGE; GE Healthcare, Piscataway, NJ, USA) $(n=18)$ and isobaric tags for relative and absolute quantitation (iTRAQ) labeling (AB Sciex, Framingham, MA, USA) followed by liquid chromatography-tandem MS ( $n=16$ ) [24]; and (3) a verification phase in an independent cohort of 20 patients by two different orthogonal techniques: Western blotting and selected reaction monitoring (SRM) [25] (Figure 1).

\section{A) Patient selection}

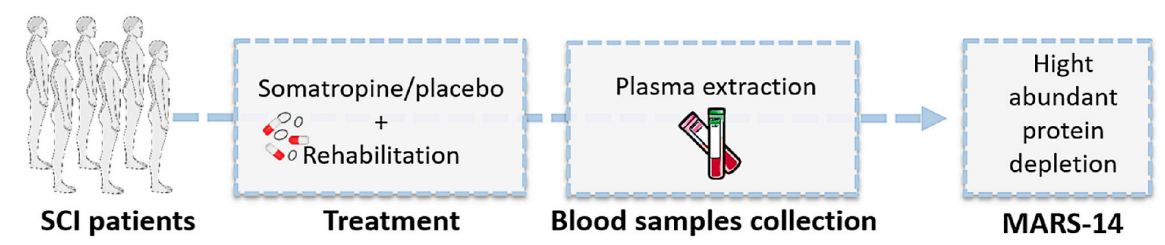

B) Discovery phase

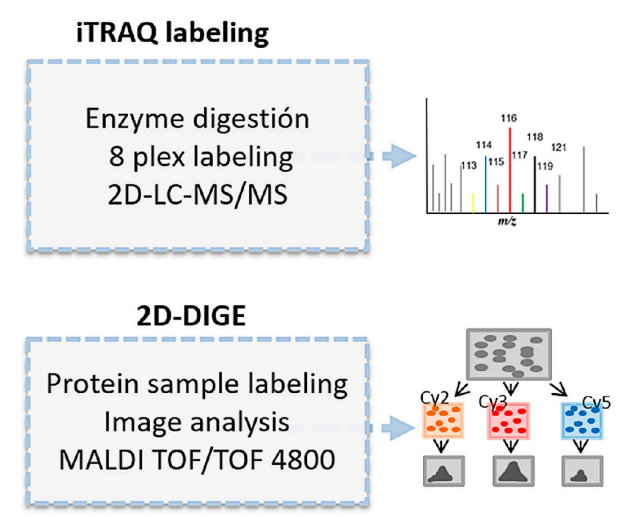

C) Verification phase

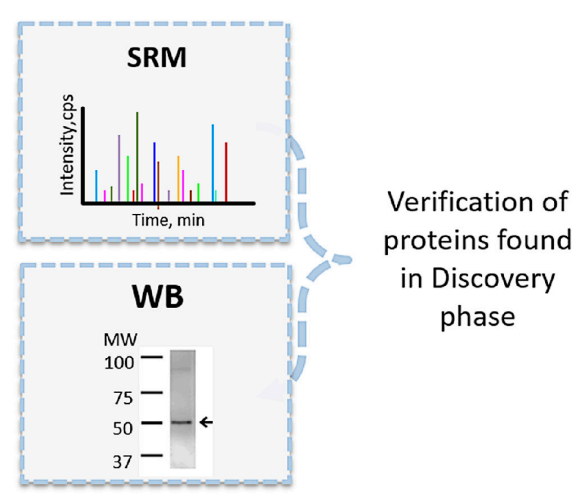

Figure 1. Experimental workflow. Stage 1 (A): Patient selection; fourteen high-abundance proteins were immunodepleted in plasma samples after extraction. Stage 2 (B): Depleted plasma samples were used in a discovery phase using two complementary proteomics techniques: isobaric tags for relative and absolute quantitation and two-dimensional fluorescence difference gel electrophoresis. Stage 3 (C): An independent cohort of patients was used in the verification phase using selected reaction monitoring. 


\subsubsection{Sample Preparation for Proteomic Analyses}

Immunodepletion was performed as described [23] using a system based on a high-performance liquid chromatography (affinity) column (HuMARS14; Agilent Technologies, Palo Alto, CA, USA) able to retain 14 abundant plasma proteins, thereby enhancing the detection and identification of low abundance proteins. Then, we performed a buffer exchange, as the elution buffer used in the immunodepletion has a high salt concentration that interferes with isoelectric focusing (IEF) and the iTRAQ protocol. Buffer exchange into Tris $20 \mathrm{mM}, 2 \mathrm{M}$ urea, $0.5 \mathrm{mM}$ phenylmethylsulfonyl fluoride (PMSF) and $0.5 \mathrm{mM}$ EDTA was performed using 3-kDa cut-off spin concentrators (Amicon Inc., Beverly, MA, USA) by centrifugation for $35 \mathrm{~min}$ at $3000 \times g$.

\subsection{2. iTRAQ}

Eight biological replicates for each treatment arm, each composed from four individuals, were independently analyzed in two 8-plex iTRAQ (Thermo Fisher Scientific Waltham, MA, USA) labeling experiments. A total of $100 \mu \mathrm{g}$ of protein from each pool was cleaned by acetone precipitation, and the pellet was dissolved in $50 \mathrm{mM}$ Tris, 4\% SDS, $50 \mathrm{mM}$ dithiothreitol (DTT; Sigma-Aldrich, Madrid, Spain) adjusted to $\mathrm{pH} 8$ and then loaded onto SDS-PAGE gels to concentrate the proteins in a single band. Proteins were digested using an in-gel digestion protocol as described [26], with some modifications. Briefly, the supernatants were run by conventional SDS-PAGE until the front entered $3 \mathrm{~mm}$ into the resolving gel. The protein band containing the whole proteome was visualized by Coomassie staining, excised, cut into cubes, subjected to reduction with $10 \mathrm{mM}$ DTT and alkylation in $50 \mathrm{mM}$ iodoacetamide, and digested overnight at $37^{\circ} \mathrm{C}$ with $60 \mathrm{ng} / \mathrm{mL}$ modified trypsin (Promega, Madison, WI, USA) at a 12:1 protein:trypsin $(w / w)$ ratio in $50 \mathrm{mM}$ ammonium bicarbonate, $\mathrm{pH} 8.8$ containing $10 \%$ acetonitrile. The resulting tryptic peptides were extracted by incubation in $12 \mathrm{mM}$ ammonium bicarbonate $\mathrm{pH} 8.8$ and later, in $0.5 \%$ Trifluoroacetic acid (TFA). TFA was added to a final concentration of $1 \%$, and the peptides were finally desalted onto C18 Oasis-HLB cartridges (Waters Corp., Medfor, MA, USA) and dried-down for further analysis.

\section{Identification by LC-MS/MS}

For stable isobaric labeling, the tryptic peptides were dissolved in triethylammonium bicarbonate buffer, and the concentration of peptides was determined by measuring amide bonds with the Direct Detect System (Millipore, Darmstadt, Germany). Equal amounts of each peptide sample were labeled using the 8-plex iTRAQ Reagents Multiplex Kit (Applied Biosystems, Foster City, CA, USA) according to the manufacturer's protocol.

iTRAQ-labeled peptides were loaded onto an LC-MS/MS system for on-line desalting onto C18 cartridges and then analysis using a C-18 reversed-phase nano-column $(75 \mu \mathrm{m} \mathrm{I.D.} \times 50 \mathrm{~cm}$, $2 \mu \mathrm{m}$ particle size, Acclaim PepMap RSLC, 100 C18; Thermo Fisher Scientific) with a continuous acetonitrile gradient consisting of $0-30 \% \mathrm{~B}$ in $360 \mathrm{~min}, 50-90 \% \mathrm{~B}$ in $3 \mathrm{~min}$ ( $\mathrm{A}=0.5 \%$ formic acid; $\mathrm{B}=90 \%$ acetonitrile, $0.5 \%$ formic acid). A flow rate of $200 \mathrm{~nL} / \mathrm{min}$ was used to elute peptides from the nano-column to an emitter nanospray needle for real-time ionization and peptide fragmentation on a Q-Exactive mass spectrometer (Thermo Fisher). An enhanced fourier Transform (FT)-resolution spectrum (resolution $=70,000$ ) followed by the MS/MS spectra from the 15 most intense parent ions were analyzed along the chromatographic run. Dynamic exclusion was set at $30 \mathrm{~s}$. To increase the proteome coverage, iTRAQ-labeled samples were also fractionated by cation exchange chromatography (Oasis HLB-MCX columns) into six fractions, which were desalted and analyzed using the same system and conditions described above. 
iTRAQ Data Analysis

For peptide identification, all spectra were analyzed with Proteome Discoverer (version 1.4.0.29) using SEQUEST-HT (both from Thermo Fisher Scientific). To perform database searching at the Uniprot database containing all sequences from human and contaminants (25 March 2018), the following parameters were selected: trypsin digestion with 2 maximum missed cleavage sites, precursor and fragment mass tolerances of $2 \mathrm{Da}$ and $0.02 \mathrm{Da}$, respectively, carbamidomethyl cysteine as fixed modification, and methionine oxidation as dynamic modifications. For iTRAQ-labeled peptides, $\mathrm{N}$-terminal and Lys iTRAQ modifications were selected as a fixed modification. Peptide identification was validated using the probability ratio method [27] with an additional filtering for precursor mass tolerance of $12 \mathrm{ppm}$. The false discovery rate (FDR) was calculated using inverted databases and the refined method [28] with an additional filtering for precursor mass tolerance of $10 \mathrm{ppm}$. Only peptides with a confidence of at least $95 \%$ were used to quantify the relative abundance of each peptide determined, as described [26]. Protein quantification from reporter ion intensities and statistical analysis of quantitative data were performed using QuiXoT, based on a statistical model [29]. In this model, protein $\log 2$-ratios are expressed in form of the standardized variables; that is, in units of standard deviation according to their estimated variances (Zq values).

\subsection{Two-Dimensional Differential Gel Electrophoresis}

Prior to 2-DIGE analysis, samples were precipitated and cleaned using the Clean-Up commercial kit (GE Healthcare). The pellet was resuspended in labeling buffer $(7 \mathrm{M}$ urea $7 \mathrm{M}, 2 \mathrm{M}$ thiourea, $4 \%$ CHAPS and $30 \mathrm{mM}$ Tris). Then, protein concentration was quantified using the Bradford-Lowry method [30].

\subsubsection{Sample Labeling}

We labeled the proteins from the depleted plasma samples using the CyDye DIGE Fluor Minimal Labeling Kit (GE Healthcare). Briefly, $50 \mu \mathrm{g}$ of each pool was labeled alternatively with 400 pmol of either $\mathrm{Cy} 3$ or $\mathrm{Cy} 5$ fluorescent dyes, and $\mathrm{Cy} 2$ was used to label a pooled internal standard with a mixture of all analyzed samples (pool of all 18 plasma samples). This internal standard was used for all 9 DIGE gels for comparison. After 30 min of incubation on ice in the dark, we quenched the reaction with $10 \mathrm{mM}$ lysine incubation for $10 \mathrm{~min}$.

\subsubsection{Two-Dimensional Electrophoresis}

Labeled samples were applied by passive rehydration (rehydration buffer: $7 \mathrm{M}$ urea $7 \mathrm{M}, 2$ $\mathrm{M}$ thiourea, 4\% 3-[(3-Cholamidopropyl)dimethylammonio]-1-propanesulfonate hydrate (CHAPS), $40 \mathrm{mM}$ DTT and ampholytes) overnight in immobilized $\mathrm{pH}$ gradient strips (IPG; $24 \mathrm{~cm}$ ), pH 4-7 (Bio-Rad Laboratories, Hercules, CA), and subjected to isoelectric focusing on an IPGphor III unit (GE Healthcare, Chicago, IL, USA) using the following program: $30 \mathrm{~min}$ at $500 \mathrm{~V}, 3 \mathrm{~h}$ at $3500 \mathrm{~V}$ (gradient), $3 \mathrm{~h}$ step and hold at $3500 \mathrm{~V}, 3 \mathrm{~h}$ at $6000 \mathrm{~V}$ (gradient), and $6000 \mathrm{~V}$ for a total of $69,000 \mathrm{~V} / \mathrm{h}$. Then, strips were subjected to two successive incubations in an equilibration buffer (1.5 M Tris-HCl $\mathrm{pH} 8.8,6 \mathrm{M}$ urea, $87 \%$ v/v glycerol, and $2 \%$ w/v SDS). In the first incubation, we added DTT (1\% $[w / v])$ to reduce the thiol groups of denatured proteins; in the second equilibration step, iodoacetamide $(2.5 \%[w / v])$ was added to alkylate reduced groups to avoid protein reoxidation.

\subsubsection{Image Acquisition and Analysis}

The second dimension was carried out on $10 \%$ running gels, and fluorescence images of the gels were acquired on a Typhoon 9400 scanner (GE Healthcare, Chicago, IL, USA) using appropriate individual excitation and emission wavelengths, filters, and photomultiplier (PTM) values that are sensitive for each of the Cy3, Cy5, and Cy2 dyes (PTM values: 480, 490, and $500 \mathrm{~nm}$, respectively).

Relative protein quantification was performed on AS and healthy valves with DeCyder software v6.5 (GE Healthcare, Chicago, IL, USA) and the multivariate statistical module EDA (Extended data 
analysis). The Differential in-gel analysis (DIA) module co-detected the 3 images of a gel (the internal standard and the two samples), measured the spot abundance in each image, and expressed these values as $\mathrm{Cy} 3 / \mathrm{Cy} 2$ and $\mathrm{Cy} 5 / \mathrm{Cy} 2$ ratios.

Then, these DIA datasets were analyzed using the Biological Variation Analysis module (BVA), which enabled the spot maps to be matched and the Cy3/Cy2 and Cy5/Cy2 ratios to be compared. Only protein spots with $>1$.3-fold differences in abundance were considered for the analysis. Then, a statistical analysis was carried out to determine the changes in protein species, with $p$-values below 0.05 accepted as significant.

Finally, a multivariate analysis was performed by Principal Component Analysis (PCA) using the algorithm included in the EDA module of the DeCyder software (version 6.5) based on the spots that matched across all the gels. The differential in-gel analysis module allowed for the co-detection and quantification of spots of the three fluorescent images of each gel. The biological variation analysis module enabled the differential abundance analysis of matched spots. Statistical analysis was performed, and $p$-values $\leq 0.05$ and fold-change $\geq 1.3$ were considered of interest. A pattern analysis hierarchical classification was obtained using the Pearson coefficient based on the spots present in $90 \%$ of all the gels.

Then, the gels were re-stained with a silver staining kit (GE-Healthcare, Chicago, IL, USA), as described previously [31].

\subsubsection{Protein Identification by Mass Spectrometry}

Differentially expressed protein spots were either excised directly from the re-stained DIGE gels or from preparative gels using $400 \mu \mathrm{g}$ of total protein, following the same procedures as described for the DIGE gels. The excised spots were digested at $37^{\circ} \mathrm{C}$ using a published protocol [32] with minor variations gel plugs that were subjected to reduction with $10 \mathrm{mM}$ dithiothreitol (Sigma Aldrich) in $50 \mathrm{mM}$ ammonium bicarbonate (99\% purity; Scharlau) and alkylation with $55 \mathrm{mM}$ iodoacetamide (Sigma Aldrich) in $50 \mathrm{mM}$ ammonium bicarbonate. Then, the gel pieces were rinsed with $50 \mathrm{mM}$ ammonium bicarbonate in 50\% methanol (gradient, HPLC grade, Scharlau) and acetonitrile (gradient, HPLC grade, Scharlau) and dried in a Speedvac. Modified porcine trypsin (sequencing grade; Promega, Madison, WI, USA) at a final concentration of $20 \mathrm{ng} / \mu \mathrm{L}$ in $20 \mathrm{mM}$ ammonium bicarbonate was added to the dry gel pieces, and the digestion proceeded at $37^{\circ} \mathrm{C}$ overnight. Finally, $70 \%$ aqueous acetonitrile and $0.1 \%$ formic acid (99.5\% purity; Sigma Aldrich) was added for peptide extraction.

After overnight digestion at $37^{\circ} \mathrm{C}$, the peptides were extracted with $60 \%$ acetonitrile (ACN) in $0.1 \%$ formic acid ( $99.5 \%$ purity; Sigma Aldrich). Then, the samples were dried in a Speedvac and resuspended in $98 \%$ water with $0.1 \%$ formic acid (FA) and $2 \%$ ACN. An aliquot of each digestion was mixed with an aliquot of the matrix solution $(3 \mathrm{mg} / \mathrm{mL} \alpha$-cyano-4-hydroxycinnamic acid: Sigma Aldrich) in 30\% ACN, 15\% 2-propanol, and 0.1\% TFA, and this mixture was pipetted directly onto the stainless steel sample plate of the mass spectrometer 384 Opti-TOF $123 \times 81 \mathrm{~mm}$ MALDI (Applied Biosystems) and dried at room temperature.

The MALDI-MS/MS data were obtained in an automated analysis loop using a 4800 Plus MALDI TOF/TOF Analyzer (Applied Biosystems). Spectra were acquired in the reflector positive-ion mode with a Nd:YAG, $355 \mathrm{~nm}$ wavelength laser at a frequency of $200 \mathrm{~Hz}$, and between 1000 and 2000 individual spectra were averaged. The experiments were acquired in a uniform mode with fixed laser intensity. For the MS/MS $1 \mathrm{kV}$ analysis mode, precursors were accelerated to $8 \mathrm{kV}$ in source 1 , and they were selected at a relative resolution of 350 Full Width at Half Maximum (FWHM) and with metastable suppression. Fragment ions generated by collision with air in a Collision-induced dissociation CID chamber were further accelerated at $15 \mathrm{kV}$ in source 2. Mass data were analyzed automatically with the 4000 Series Explorer Software version 3.5.3 (Applied Biosystems Foster City, CA, USA). Internal calibration of MALDI-TOF mass spectra was performed using two trypsin autolysis ions with $\mathrm{m} / \mathrm{z}=842.510$ and $\mathrm{m} / \mathrm{z}=2211.105$. For the calibrations in the MS/MS mode, the fragment ion spectra obtained from Glub-fibrinopeptide were used (4700 Cal Mix, Applied Biosystems). MALDI-MS and MS/MS data were 
combined through the GPS Explorer Software (Version 3.6) to search a non-redundant protein database (Swissprot 56.5) using the Mascot software (version 2.2: Matrix Science Inc., Boston, MA, USA) [33]. The following parameters were employed: $50 \mathrm{ppm}$ precursor tolerance; $0.6 \mathrm{Da}$ MS/MS fragment tolerance; 1 missed cleavage permitted; and with carbamidomethyl cysteines and methionine oxidation as a modification. MALDI-MS (/MS) spectra and database search results were manually inspected using the aforementioned software. For combined MS and MS/MS data, identifications were accepted when Confidence Interval (C.I. \%) of GPS software was 95\% or higher. Since Protein Scores and Ion Scores from different searches cannot be directly compared, GPS software calculates this C.I. \% in order to combine results from MS and MS/MS database searches. This coefficient value means that the probability that the observed match is a random event is lower than $5 \%$. For PMF spectra, identifications were also accepted when (C.I. \%) of GPS software was 99\% or higher. Alternatively, the ppw files were obtained from 4000 series explorer software (ABSciex, Madrid, Spain). Peptides were analyzed in a 4800 Plus MALDI TOF/TOF (AB Sciex, Madrid, Spain) mass spectrometer, and protein identifications were achieved by subjecting the obtained MS/MS spectra to the MASCOT 2.2 (Matrix Science Inc., Boston, MA, USA) search engine, using the Swissprot 56.2 database with $50 \mathrm{ppm}$ precursor tolerance, $0.6 \mathrm{Da}$ MS/MS fragment tolerance, carbamidomethyl cysteine as fixed modification, oxidized methionine as variable modification, and allowing 1 missed cleavage.

\subsection{Western Blotting}

Twenty samples from an independent cohort of patients were used for Western blot analysis-10 patients were treated with somatropin and 10 were treated with placebo, at baseline and at 6 months. Proteins $(25 \mu \mathrm{g})$ were separated by $12 \%$ SDS-PAGE and analysis was carried out using anti-vitamin D binding protein (GC) (1/1000), anti-plasminogen (PLG) (1/2000), antibodies, and species-specific secondary antibodies, all from Abcam (Cambridge, UK). Relative protein levels were determined by densitometry using ImageQuant software (Amersham, Uppsala, Sweden).

\subsection{Selected Reaction Monitoring}

Following our previously published protocol [34,35], samples were reduced with $100 \mathrm{nM}$ DTT in $50 \mathrm{mM}$ ammonium bicarbonate (99\% purity; Scharlau, Barcelona, Spain) for $30 \mathrm{~min}$ at $37^{\circ} \mathrm{C}$ and alkylated with $550 \mathrm{mM}$ iodoacetate in $50 \mathrm{mM}$ ammonium bicarbonate for $20 \mathrm{~min}$ at room temperature. Proteins were digested in $50 \mathrm{mM}$ ammonium bicarbonate, $15 \%$ acetonitrile (LC-MS grade; Scharlau, Barcelona, Spain) with sequencing-grade modified porcine trypsin (Promega, Madison, WI, USA) at a final concentration of 1:50. After digestion at $37{ }^{\circ} \mathrm{C}$ overnight, $2 \%$ formic acid $(99.5 \%$ purity; Sigma-Aldrich) was added, and samples were cleaned using Pep-Clean spin columns (Pierce, Rockville, MD, USA). Tryptic digests were dried in a Speed Vac and resuspended in $2 \%$ acetonitrile, $2 \%$ formic acid prior to MS analysis. The LC-MS/MS system consisted of a TEMPO nano LC system (Applied Biosystems) combined with a nano LC autosampler and coupled to a modified triple quadrupole MS system (Applied Biosystems 4000 QTRAO LC/MS/MS). Three replicate injections (4 $\mu \mathrm{L}$ containing $20 \mu \mathrm{g}$ of protein) were performed per sample using mobile phase A ( $2 \%$ acetonitrile/ $98 \%$ water, $0.1 \%$ formic acid) with a flow rate of $10 \mu \mathrm{L} / \mathrm{min}$ for $5 \mathrm{~min}$. Peptides were loaded onto a $\mu$-Precolumn Cartridge

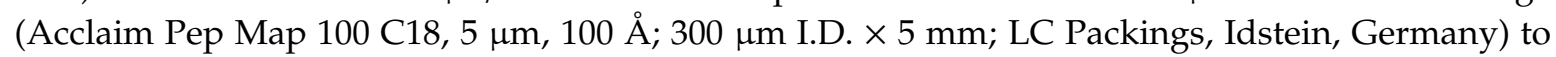
pre-concentrate and desalt samples. Reverse phase LC was achieved on a C18 column (Onyx Monolithic C18, $150 \times 0.1 \mathrm{~mm}$ I.D.; Phenomenex, Torrance, CA, USA) in a gradient of phase A and phase B ( $98 \%$ acetonitrile $/ 2 \%$ water, $0.1 \%$ formic acid). Peptides were eluted at a flow rate of $900 \mathrm{~nL} / \mathrm{min}$ in the following steps: $2-15 \%$ B for $2 \mathrm{~min}, 15-30 \%$ B for $18 \mathrm{~min}, 30-50 \%$ B for $5 \mathrm{~min}, 50-90 \%$ B for $2 \mathrm{~min}$, and finally $90 \%$ B for $3 \mathrm{~min}$. Then, the column was regenerated with $2 \%$ B for 15 additional minutes. Both the 2-(2,2,6,6-tetramethyl piperidine-1-oxyl (TEMPO) nano LC and 4000 QTRAP system were controlled by Analyst Software v.1.4.5. The mass spectrometer was set to operate in positive ion mode with an ion spray voltage of $2800 \mathrm{~V}$ and a nanoflow interface heater temperature of $150{ }^{\circ} \mathrm{C}$. Source gas 1 and curtain gas were set to 20 and 20 psi, respectively, and nitrogen was applied as both curtain 
and collision gases. Collision energy was optimized to obtain maximum transmission efficiency and sensitivity for each SRM transition. Two or three transitions per peptide were monitored during an individual sample analysis. They were acquired at unit resolution in both Q1 and Q3, with dwell times from 40 to $120 \mathrm{~ms}$, resulting in cycle times of $4.0957 \mathrm{~s}$. The IntelliQuan algorithm, included in Analyst 1.4.5 software, was used to calculate abundances based on peak areas after integration. To calculate significant differentially abundant proteins, we first calculated the concentration for each peptide according the following equation ( $\left.\mathrm{fmoL} / \mathrm{H}{ }^{*} 50\right)$ corresponding to $2 \mu \mathrm{g}$ of digested sample. Secondly, we calculated an average of all identified peptides. Significance was considered with a $p$-value $\leq 0.05$ (Table 5).

\subsection{Statistical Analysis}

Statistical analyses were performed using SPSS 15.0 for windows software (SPSS Inc., Chicago, IL, USA). Nonparametric analyses were performed to analyze data. The Wilcoxon test was used in case of related samples and the Mann-Whitney $U$ test was used in case of independent samples. Results were expressed as means \pm standard deviation (SD). For iTRAQ analysis, we considered the differentially expressed proteins identified with at least 1 peptide and log2-ratios expressed in the form of the standardized variables $(\mathrm{Zq} \pm 1.5)$ with $p$-values $\leq 0.05$, with $\mathrm{Zq}$ being the mean for the 2 replicates versus the placebo group. In relation to the 2D-DIGE analysis, a fold change of 1.3 was imposed and $p \leq 0.05$ was considered as significant differences. For SRM analysis, we considered the mean of all the peptides separately used to identify the protein in each case. Significance was considered with a $p$-value $\leq 0.05$.

Pearson's correlation coefficient was calculated to analyze the association between two variables. In groups treated with somatropin, several correlations were performed-motor score and IGF-1, and motor score with GC-both at 6 months of treatment. These correlations could help us better understand the grouping of the subjects after PCA analysis. Significance was accepted at $p \leq 0.05$ in all cases.

\section{Results}

We sought to evaluate whether protein alterations could identify those SCI individuals who will respond to somatropin or reahabilitation treatment. We performed quantitative proteomics analyses in a transversal study using plasma samples collected at baseline (collected before treatment) and at 6 months. Table 3 describes patients' clinical characteristics. No significant differences between the treatment and placebo groups were found for sex and age. Likewise, motor score parameters and IGF-1 levels were not significantly different between groups (at baseline and at 6 months).

We re-measured some clinical parameters after 6 months to test for improvements in patients who received somatropin or placebo. Regarding the evolution of motor score, we observed a relatively slight improvement in patients treated with somatropin (Figure 2A). These patients showed an increase both in total motor score (Figure 2A) and lower limb score (Figure 2B), whereas no significant improvements were observed in patients treated with placebo (Figure 2A,B). Analysis of IGF-1 levels at 6 months revealed an increase in the somatropin treatment group but not in the placebo group (Figure 2C). 
A

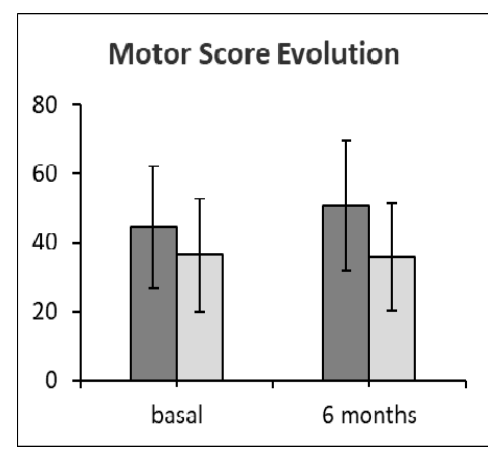

B

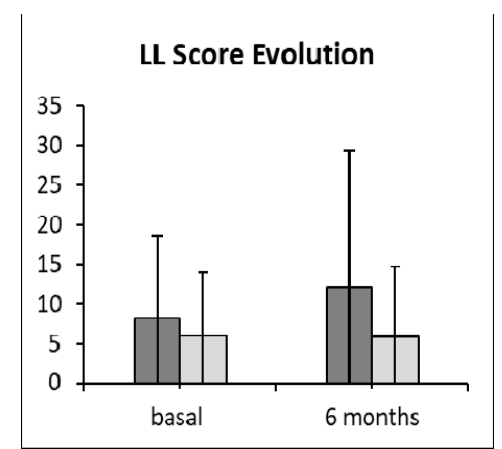

C

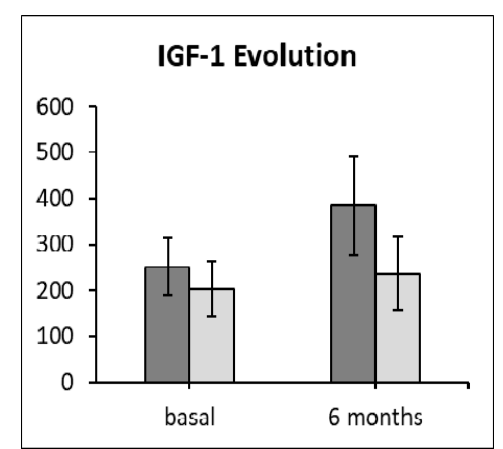

Figure 2. (A) Mean per group of motor score changes at different time points: basal and 6 months. (B) Mean per group of lower limb (LL) score changes at different times: basal and 6 months. (C) Evolution of insulin growth factor-1 (IGF-1) in each study group at different times: basal and 6 months. Dark gray bar: growth hormone $(\mathrm{GH})$ group; light gray bar: placebo group.

We searched for molecular changes occurring in the plasma proteome of patients during somatropin treatment using iTRAQ and 2D-DIGE proteomic approaches. The iTRAQ liquid chromatography-tandem mass spectrometry strategy allowed us to identify 984 proteins in total, of which 21 were differentially expressed (Table 3). The 2D-DIGE analysis revealed 11 protein spots differentially expressed between the two groups, which correspond to eight proteins (Table 4). Of special note, the eight proteins were not detected as significantly expressed by iTRAQ, so the combination of these two different and complementary proteomics techniques guarantees a more extensive coverage of quantified proteins [36]. To validate these changes, and considering the fold-change and the possible involvement of molecular mechanisms related to SCI pathology, we analyzed 10 proteins by SRM and five by Western blotting in an independent cohort of 20 patients with a good response in the motor score. Two of the five proteins were verified by Western blotting (PLG, GC) (Figure 3A), and three of the 10 proteins were verified by SRM (APOA1, C4B, and ITIH4) (Figure 3B).

Table 3. Differentially expressed proteins identified by isobaric tags for relative and absolute quantitation (iTRAQ). Accession number (AccN), protein name and abbreviation (Abb.) according to Uniprot database. N: number of unique peptides. Zq: mean of log2-ratios expressed in form of the standardized variables for two replicates.

\begin{tabular}{|c|c|c|c|c|c|c|c|}
\hline AccN & Protein Name & $A b b$ & Functions & $\mathbf{N}$ & $\begin{array}{l}\mathrm{Zq} \\
\text { Placebo } \\
\text { Group }\end{array}$ & $\begin{array}{l}\mathrm{Zq} \mathrm{GH} \\
\text { Group }\end{array}$ & Power \\
\hline P00747 & Plasminogen & PLMN & $\begin{array}{l}\text { Blood coagulation/Catalytic } \\
\text { activity/Extracellular matrix } \\
\text { disassembly }\end{array}$ & 39 & 2.19 & 0.33 & 0.999 \\
\hline P02760 & Protein AMBP & AMBP & $\begin{array}{l}\text { Metabolic process/Catalytic } \\
\text { activity/Negative regulation } \\
\text { of immune response }\end{array}$ & 13 & 2.33 & -0.01 & 1.000 \\
\hline P11226 & Mannose-binding protein C & MBL2 & $\begin{array}{l}\text { Acute-phase } \\
\text { response/Complement } \\
\text { activation/Innate immunity }\end{array}$ & 9 & -0.56 & -3.30 & 0.999 \\
\hline Q01459 & Di-N-acetylchitobiase & DIAC & Glycosidase/Hydrolase & 3 & -0.57 & -1.92 & 0.999 \\
\hline
\end{tabular}


Table 3. Cont

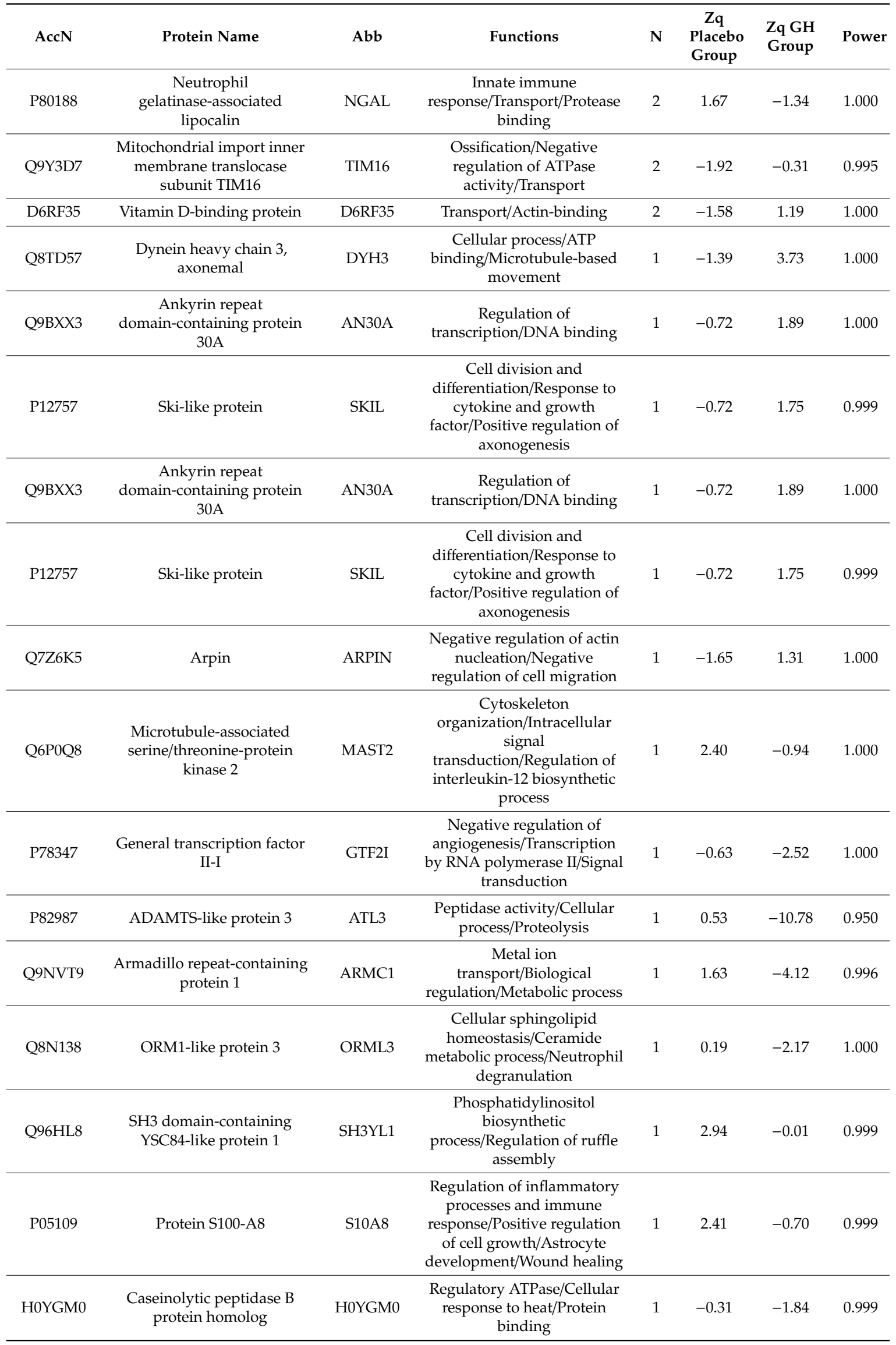


Table 4. Differentially expressed proteins identified by two-dimensional fluorescence difference gel electrophoresis (2D-DIGE). Differences in fold change are shown as average ratio (AvR). Protein name and accession number $(\mathrm{AccN})$ according to Uniprot database are listed.

\begin{tabular}{|c|c|c|c|c|c|c|c|}
\hline & \multirow[t]{2}{*}{ AccN } & \multirow[t]{2}{*}{ Protein Name } & \multirow[t]{2}{*}{ Functions } & \multicolumn{2}{|c|}{$\begin{array}{l}\text { Somatropin } \\
t 0 \text { vs. } t 1\end{array}$} & \multicolumn{2}{|c|}{$\begin{array}{l}\text { Placebo } \\
t 0 \text { vs. } t 1\end{array}$} \\
\hline & & & & AvR & $p$-Value & AvR & $p$-Value \\
\hline 1 & Q14624 & $\begin{array}{c}\text { Inter-alpha-trypsin } \\
\text { inhibitor heavy chain } \mathrm{H} 4\end{array}$ & $\begin{array}{l}\text { Serine-type endopeptidase } \\
\text { inhibitor activity }\end{array}$ & 1.55 & $7.70 \times 10^{-3}$ & & \\
\hline 2 & Q14624 & $\begin{array}{c}\text { Inter-alpha-trypsin } \\
\text { inhibitor heavy chain } \mathrm{H} 4\end{array}$ & $\begin{array}{l}\text { Serine-type endopeptidase } \\
\text { inhibitor activity }\end{array}$ & & & -3.82 & 0.0106 \\
\hline 3 & P0C0L5 & Complement C4-B & $\begin{array}{c}\text { Inflammatory } \\
\text { response/Complement } \\
\text { activation }\end{array}$ & -1.24 & 0.0107 & & \\
\hline 4 & P02647 & Apolipoprotein AI & Cholesterol transport & 1.65 & 0.0293 & & \\
\hline 5 & P02647 & Apolipoprotein AI & Cholesterol transport & & & -1.66 & 0.0474 \\
\hline 6 & P00450 & Ceruloplasmin & Oxidoreductase & -1.15 & 0.0139 & & \\
\hline 7 & P00450 & Ceruloplasmin & Oxidoreductase & & & -1.5 & 0.0175 \\
\hline 8 & P36955 & $\begin{array}{c}\text { Pigment } \\
\text { epithelium-derived factor }\end{array}$ & $\begin{array}{l}\text { Serine-type endopeptidase } \\
\text { inhibitor activity }\end{array}$ & & & -1.19 & 0.0472 \\
\hline 9 & P02649 & Apolipoprotein E & Cholesterol metabolism & & & -1.11 & 0.0181 \\
\hline 10 & P02790 & Hemopexin & Metalloprotease & & & -3.13 & 0.0332 \\
\hline 11 & P04217 & Alpha-1B-glycoprotein & $\begin{array}{c}\text { Neutrophil and platelet } \\
\text { degranulation }\end{array}$ & & & -1.27 & 0.00545 \\
\hline
\end{tabular}

A

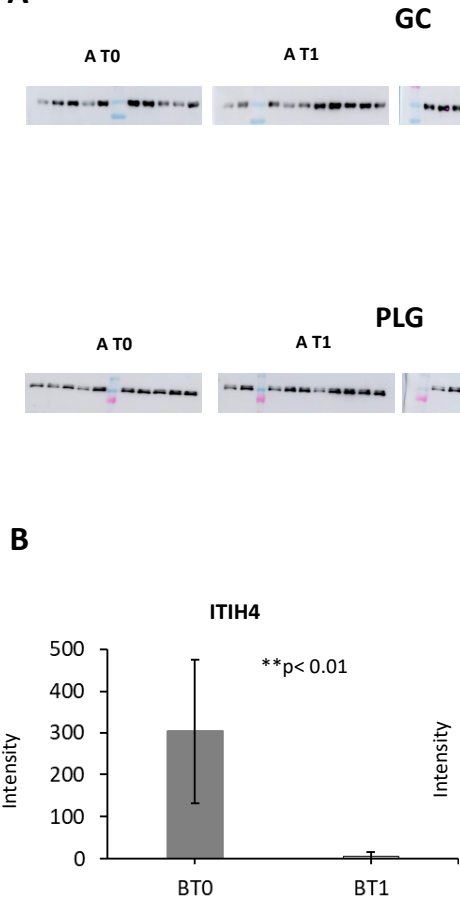

GC

B то

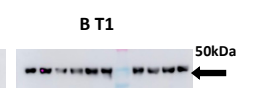

в то

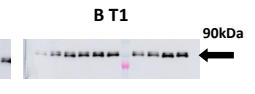

APOA1

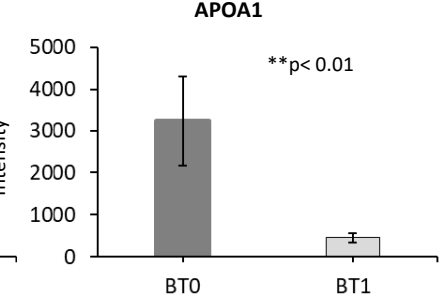

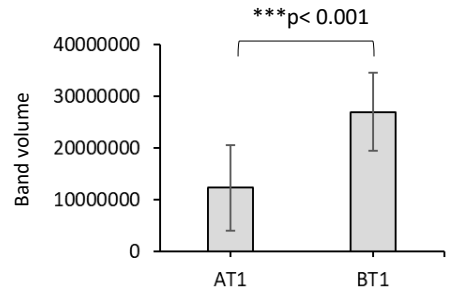

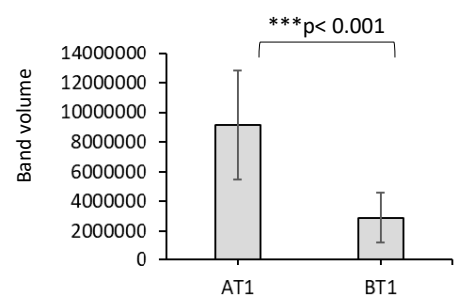

C4B

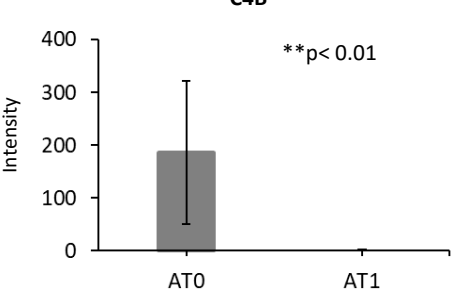

Figure 3. (A) Verification of GC and anti-plasminogen (PLG) by Western blotting. Volume represents band intensity band determined by Image Quant QL software: AT0 (group treated with somatropin, at baseline), AT1 (group treated with somatropin at 6 month), BT0 (group treated with placebo, at baseline), and BT1 (group treated with placebo at 6 months). (B) Verification of ITIH4, APOAI, and C4B by selected reaction monitoring. AT0 (group treated with GH, at baseline time). AT1 (group treated with GH at 6 months), BT0 (group treated with placebo, at baseline), BT1 (group treated with placebo at 6 months). 
Non-parametric test (Mann-Whitney U test) of PLG $(\approx 90 \mathrm{kDa})$ and GC $(50 \mathrm{kDa})$ revealed significant differences between the somatropin and placebo groups at 6 months after the start of treatment $(p<0.001$ and $p<0.001$, respectively), with the levels of PLG increased in the somatropin-treated group and the levels of GC decreased. Of the three proteins validated by SRM (Figure 3B) (Table 5), the data obtained corroborated the proteomics results. ITIH4 and APOA1 were downregulated in the placebo group after 6 months, and C4B was likewise downregulated in the somatropin group.

Table 5. Monitored proteins by selected reaction monitoring (SRM) in plasma samples. Shown are measured peptides for each protein. Mean per peptide and mean per protein. Concentration expressed as fmol L/H $* 50$ corresponded to $2 \mu \mathrm{g}$ of digested sample. Abb: protein abbreviation; AccN: accession number. APOA1: apolipoprotein A1; CO4B: complement C4-B; ITIH4: inter-alpha-trypsin inhibitor heavy chain $\mathrm{H} 4$.

\begin{tabular}{|c|c|c|c|c|c|c|c|}
\hline \multirow{2}{*}{ AccN } & \multirow{2}{*}{ Function } & \multirow{2}{*}{$\mathbf{A b b}$} & \multirow{2}{*}{ Peptide Sequence } & \multirow{2}{*}{ Peptide Means } & \multirow{2}{*}{ Protein Means } & \multicolumn{2}{|c|}{$p$-Value } \\
\hline & & & & & & Bt0 vs. Bt1 & At0 vs. At1 \\
\hline \multirow{2}{*}{ Q14624 } & \multirow{2}{*}{ Protease inhibitor } & \multirow{2}{*}{ ITIH4 } & ANTVQEATFQMELPK & $595.12 \pm 12.81$ & \multirow{2}{*}{$302.71 \pm 6.66$} & \multirow{2}{*}{$<0.001$} & \multirow{2}{*}{ NA } \\
\hline & & & IPKPEASFSPR & $10.30 \pm 0.51$ & & & \\
\hline \multirow{2}{*}{ P0C0L5 } & \multirow{2}{*}{$\begin{array}{l}\text { Complement activation; } \\
\text { Inflammatory response }\end{array}$} & \multirow{2}{*}{$\mathrm{CO} 4 \mathrm{~B}$} & VLSLAQEQVGGSPEK & $31.62 \pm 3.03$ & \multirow{2}{*}{$186.82 \pm 1.65$} & \multirow{2}{*}{ NA } & \multirow{2}{*}{$<0.001$} \\
\hline & & & AEMADQAAAWLTR & $342.03 \pm 0.27$ & & & \\
\hline P02647 & Cholesterol transport & APOA1 & DYVSQFEGSALGK & $3234.20 \pm 456.42$ & $3234.20 \pm 456.42$ & $<0.001$ & NA \\
\hline
\end{tabular}

The biological implication of the differentially expressed proteins detected both by 2D-DIGE analysis and by iTRAQ analysis were analyzed using DAVID Bioinformatics Resources 6.7 software. Interestingly, the validated proteins that belonged to one cluster that corresponded to the extracellular region showed an enrichment score $=7.11$, and $p=2.9 \times 10^{-10}$. Functional analysis of the differentially expressed proteins was explored using the String v11.0 webtool (Figure 4A). According to the molecular function and the pathway analysis performed, it is important to note that proteins validated by Western blotting and SRM corresponded to the extracellular region and showed a significant interaction with each other with a false discovery rate $=4.82 \times 10^{-7}$ (Figure $4 \mathrm{~A}$ ).

We also performed PCA with the validated proteins (Figure 4B), which showed the correct grouping of patients treated with placebo. By contrast, patients treated with somatropin formed two sub-groups: a positive response $(\mathrm{GH}+)$ and a non-response $(\mathrm{GH} \pm)$ to somatropin. These results reveal that patients with no response to somatropin are similar to patients treated with placebo.

According to the PCA, the five proteins validated by Western blotting and SRM analysis were divided into two panels: (i) indicator of response to somatropin treatment: GC, C4B, and PLG (Figure 4C) and (ii) positive response to rehabilitation (this went down well in the placebo group): GC, APOA1, and ITIH4 (Figure 4D).

Receiver operating characteristic (ROC) curve analysis showed a good sensitivity and specificity for both panels. The indicator of response to somatropin panel could discriminate somatropin from placebo treatment with an area under the ROC curve (AUC) of 0.930 (Figure 5A). The indicator of positive response to rehabilitation panel had an AUC of 0.963 (Figure 5B).

To search for links between clinical parameters and the validated proteins, we performed correlation analyses of the proteins validated and motor score levels. We found that GC had a negative correlation with motor score levels in patients at 6 months of treatment $(r=-0.643)$ (Figure 5C). In addition, we found a negative correlation between IGF-1 and motor score $(r=-0.269)$ (Figure 5D). These results indicate that higher levels of IGF-1 and GC imply a worse somatropin treatment response. 
A

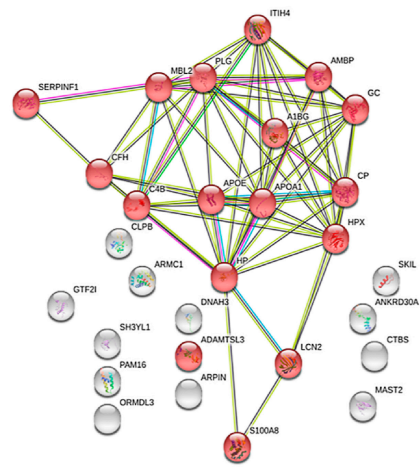

C

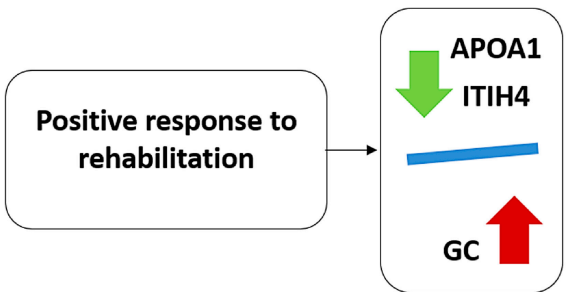

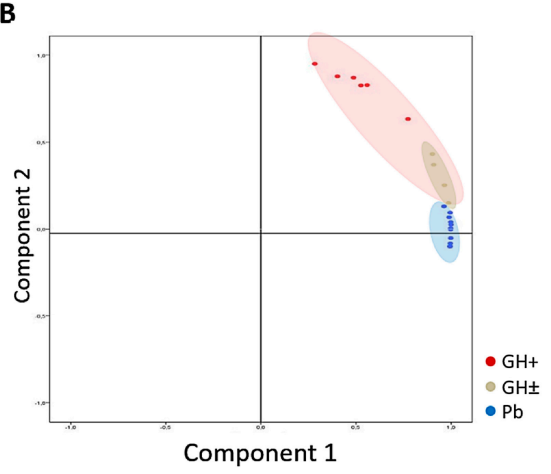

D

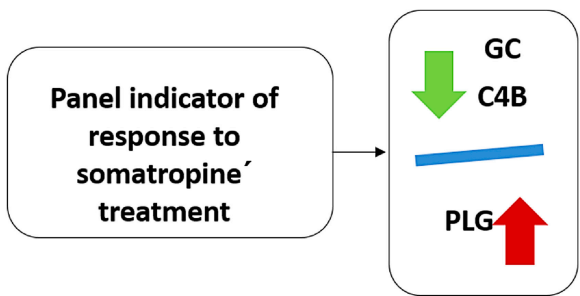

Figure 4. (A) Pathway analysis of the differentially expressed proteins. Protein-protein interaction networks were studied with STRING v11.0 software. Proteins with red circles correspond to proteins that are implicated on the extracellular region. (B) Principal Component Analysis with the validated proteins showed the correct grouping of patients treated with placebo $(\mathrm{Pb})$. Patients treated with somatropin formed two sub-groups: a positive response $(\mathrm{GH}+)$ and a non-response $(\mathrm{GH} \pm)$ to somatropin. (C) Panel of response to rehabilitation which is composed of three proteins (APOA1, ITIH4, GC) showing downregulation in the placebo group at 6 months. (D) Panel indicator of response to somatropin treatment: GC and C4B were downregulated, whereas PLG was upregulated at 6 months.

A
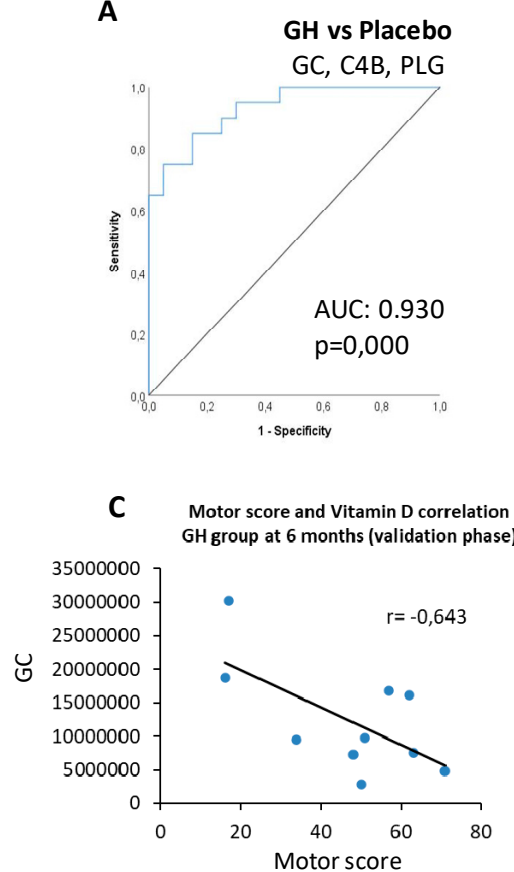

B
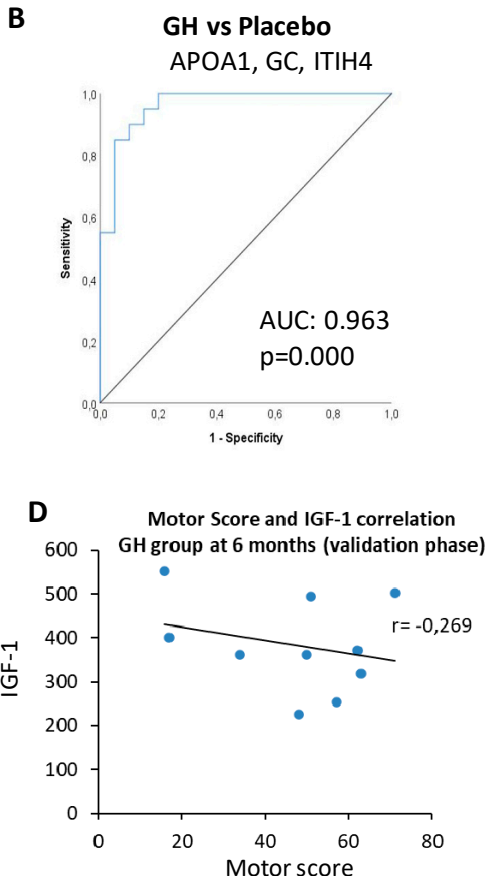

Figure 5. (A) Receiver operating characteristic (ROC) curve of the panel indicator of response to somatropin formed by three proteins. Area under the ROC curve (AUC) and $p$-values are shown. (B) ROC curve of the rehabilitation panel formed by three proteins. AUC and $p$-value are shown. (C) Negative correlation between somatropin and motor score. (D) Negative correlation between IGF-1 and motor score. 


\section{Discussion}

No curative treatment yet exists for SCI, and rehabilitation is the only therapeutic option that can contribute to functional improvement in patients. Mass spectrometry proteomics has become a powerful tool in biomedical research over the past 20 years [37], including its applications for studying the differential proteome in SCI [38,39]. In this context, here, we utilized an unbiased proteomic approach with two independent but complementary techniques (iTRAQ and 2D-DIGE) to search for protein biomarkers as indicators of improvement associated with the administration of GH in patients with SCI. These approaches revealed 21 and eight differentially expressed proteins, respectively, with GH treatment, and five of these protein biomarkers were confirmed by SRM and Western blotting in an independent cohort of 20 patients. These evident differential changes to the SCI proteome allow us to molecularly characterize several processes implicated in GH treatment and associated with SCI.

All six proteins are related to the extracellular region (the space external to the outermost structure of a cell), pointing to the activation of this pathway in patients with SCI treated with GH. Moreover, ROC curves showed good sensitivity and specificity for these protein markers, pointing to the potential value of these indicators to classify patients with SCI according to treatment. A panel of three proteins (C4B, GC, and PLG) was altered in the plasma from patients treated with somatropin and might have a potential predictive value in estimating the improvement of $\mathrm{SCI}$ after somatropin treatment, which is also supported by the ROC curve value (AUC $=0.930$ ) (Figure $5 \mathrm{~A}$ ) and by PCA analysis (Figure $4 \mathrm{~B}$ ).

We found a different proteomic signature made up of three proteins (APOA1, GC, and ITIH4) that are differentially expressed in the placebo group, and whose levels might be related to positive response to rehabilitation. Again, this result is supported by the ROC curve analysis (AUC $=0.963$ ) (Figure 5B).

\subsection{Panel Indicator of Response to Somatropin Treatment}

The complement system, which includes C4B, plays a critical role in development, homeostasis, and regeneration in the central nervous system (CNS) throughout life [40]. The complement cascade is at the interface of the coagulation and inflammation pathways and is operative in acute neurological disorders, such as SCI and traumatic brain injury [41]. This is in line with our proteomics data, which showed an upregulation of $\mathrm{C} 4 \mathrm{~B}$ along the time in the treated group.

LG is a glycoprotein that circulates in plasma as a zymogen and, when converted to proteolytically active plasmin, dissolves preformed fibrin clots and extracellular matrix components [42]. A regulatory role for PLG has been described in complement and coagulation cascades [43], and it is also implicated in inflammation pathways that occur in SCI [40]. Those of the IGF-1 protein include controlling the regeneration of injured peripheral nerves, reducing the progression of cell death, inducing progenitor cell differentiation, and promoting neurite outgrowth [44,45]. Furthermore, it has been described that PLG activators play a functional role in synaptic plasticity associated with the crossed phrenic phenomenon and recovery of respiratory function following SCI [46]. We found that IGF-1 levels increased in patients treated with somatropin. This might be due to the action of somatropin, which could be reflected in the higher PLG levels.

It is important to note that bone loss occurs rapidly during the first 4-6 months to one year post SCI, with a $40 \%$ reduction in sub-lesional bone mineral density reported at two years post injury [47,48]. It has been described that osteoporosis following SCI results from the deficiency of GC and by the pituitary suppression of TSH $[49,50]$. This is in accord with our results, as we found a decrease in plasma GC at 6 months in patients treated with somatropin. This is also corroborated by our findings of a negative correlation between motor score and GC level, with higher levels of vitamin D binding protein implying a worse response to somatropin treatment.

\subsection{Panel Indicator of Positive Response to Rehabilitation}

APOA1 and ITHIH4 abundance were reduced in the placebo group over time. Nevertheless, the patients in this group showed an improvement in their physical condition as assessed by their motor 
score values, which is likely due to the rehabilitation that they received along the study. ITIH4 is a serine protease inhibitor involved in extracellular matrix stabilization and in inflammatory response [51]. ITIH4 binds hyaluronan, which is an integral component of the CNS extracellular matrix and modulates the level of free hyaluronan [52]. In the acute phase of SCI, the CNS is damaged and the accumulation of free hyaluronan contributed to the inhibition of re-myelination and axonal regeneration, as well as the onset of inflammation [53]. As shown by our results, inflammation and extracellular matrix components may be stabilized and improved during the rehabilitation therapy, and therefore, ITIH4 levels decrease.

APOA1 is believed to control inflammatory activities after CNS injury and it ameliorates the tissue damage that accompanies uncontrolled inflammation, and it also promotes axonal repair [54]. Our results are similar to those in the literature, as in the placebo group, APOA1 was higher at baseline than after 6 months. The inflammation phase of SCI occurs during the first months of injury, in which APOA1 is described to be downregulated [55].

In this study, we highlight the potential of plasma proteomics to discover novel indicators of response to somatropin treatment or response to rehabilitation in patients with SCI. Our study provides a subset of promising markers of response to somatropin treatment or response to rehabilitation, as suggested by the high AUC values. These panels could shed some light on the SCI regulatory mechanisms triggered in response to somatropin treatment and rehabilitation. Indeed, the proteins described here are all implicated in inflammation, homeostasis, and coagulation processes, which are initial and secondary events of SCI. Furthermore, a remarkable feature of this study is the potential of rehabilitation to improve function in patients.

The major limitation to our study is the sample size, and larger samples will be needed to confirm the potential value of the protein indicators described here. Future efforts should be directed toward performing a functional analysis of these candidate markers to assess their potential role in improving function in patients with SCI. A prospective study will be required to determine the clinical utility of these proteins as potential biomarkers to distinguish those patients who will have a positive response to GH treatment and those who will be positive responders to rehabilitation without the need for GH treatment.

Author Contributions: Conceptualization, A.O., M.G.B.; data curation, A.E.-R., F.G.-D.; formal analysis T.M.-R., T.S.-O., F.G.-D.; funding acquisition, A.O., M.G.B.; investigation, T.M.-R., T.S.-O., F.G.-D., L.M.-A., N.C.-A., R.M.-L., G.H.-F., J.A.L.; methodology, A.O., M.G.B.; project administration, A.O., M.G.B.; resources, A.E.-R., A.O., J.A.L.; supervision, A.O., M.G.B.; validation, L.M.-A, N.C.-A., R.M.-L.; visualization, T.M.-R., T.S.-O., L.M.-A.; writing-original draft preparation, T.M.-R., T.S.-O., M.G.B.; writing-review and editing, T.M.-R., T.S.-O., A.E.-R., F.G.-D, L.M.-A., N.C.-A., R.M.-L., G.H.-F., J.A.L, A.O., M.G.B. All authors have read and agreed to the published version of the manuscript.

Funding: This study has been funded by Instituto de Salud Carlos III through the projects PI14/01917, PI18/00995, PT13/0001/0013 (Co-funded by European Regional Development Fund/European Social Fund) "Investing in your future". Redes Temáticas de Investigación Cooperativa (FONDOS FEDER, RD12/0042/0071). Sociedad Española de Cardiología para la Investigación Básica 2017. Proyecto Fundación-Mapfre 2013. Grant PRB3 (IPT17/0019-ISCIII-SGEFI/ERDF). "Ministerio de Sanidad y Politicas Sociales" of Spain and the "Fondo Europeo de Desarrollo Regional-FEDER" (project: TRA-173). These results are aligned with the Spanish initiative on the Human Proteome Project (SpHPP).

Conflicts of Interest: The authors declare no conflict of interest.

\section{References}

1. Bárbara-Bataller, E.; Méndez-Suárez, J.L.; Alemán-Sánchez, C.; Sánchez-Enríquez, J.; Sosa-Henríquez, M. Change in the profile of traumatic spinal cord injury over 15 years in Spain. Scand. J. Trauma Resusc. Emerg. Med. 2018, 26, 27. [CrossRef] [PubMed]

2. Schuld, C.; Franz, S.; Brüggemann, K.; Heutehaus, L.; Weidner, N.; Kirshblum, S.C.; Rupp, R. International standards for neurological classification of spinal cord injury: Impact of the revised worksheet (revision 02/13) on classification performance. J. Spinal. Cord Med. 2016, 39, 504-512. [CrossRef] [PubMed] 
3. Alizadeh, A.; Dyck, S.M.; Karimi-Abdolrezaee, S. Traumatic spinal cord injury: An overview of pathophysiology, models and acute injury mechanisms. Front. Neurol. 2019, 10, 282. [CrossRef] [PubMed]

4. Jutzeler, C.R.; Streijger, F.; Aguilar, J.; Shortt, K.; Manouchehri, N.; Okon, E.; Hupp, M.; Curt, A.; Kwon, B.K.; Kramer, J.L.K. Sensorimotor plasticity after spinal cord injury: A longitudinal and translational study. Ann. Clin. Transl. Neurol. 2019, 6, 68-82. [CrossRef]

5. Fawcett, J.W.; Curt, A.; Steeves, J.D.; Coleman, W.P.; Tuszynski, M.H.; Lammertse, D.; Bartlett, P.F.; Blight, A.R.; Dietz, V.; Ditunno, J.; et al. Guidelines for the conduct of clinical trials for spinal cord injury as developed by the ICCP panel: Spontaneous recovery after spinal cord injury and statistical power needed for therapeutic clinical trials. Spinal Cord 2007, 45, 190-205. [CrossRef]

6. Huang, H.; Young, W.; Skaper, S.; Chen, L.; Moviglia, G.; Saberi, H.; Al-Zoubi, Z.; Sharma, H.S.; Muresanu, D.; Sharma, A.; et al. Clinical neurorestorative therapeutic guidelines for spinal cord injury (IANR/CANR version 2019). J. Orthop. Transl. 2020, 20, 14-24. [CrossRef]

7. Martinez-Moreno, C.G.; Calderon-Vallejo, D.; Harvey, S.; Aramburo, C.; Quintanar, J.L. Growth Hormone $(\mathrm{GH})$ and Gonadotropin-Releasing Hormone $(\mathrm{GnRH})$ in the central nervous system: A potential neurological combinatory therapy? Int. J. Mol. Sci. 2018, 19, 375. [CrossRef]

8. Lopez, J.; Quan, A.; Budihardjo, J.; Xiang, S.; Wang, H.; Kiron, K.; Cashman, C.; Lee, W.P.A.; Hoke, A.; Tuffaha, S.; et al. Growth Hormone improves nerve regeneration, muscle re-innervation, and functional outcomes after chronic denervation injury. Sci. Rep. 2019, 9, 3117. [CrossRef]

9. Hua, K.; Forbes, M.E.; Lichtenwalner, R.J.; Sonntag, W.E.; Riddle, D.R. Adult-onset deficiency in growth hormone and insulin-like growth factor-I alters oligodendrocyte turnover in the corpus callosum. Glia 2009, 57, 1062-1071. [CrossRef]

10. Gibney, J.; Healy, M.L.; Sönksen, P.H. The growth hormone/insulin-like growth factor-I axis in exercise and sport. Endocr. Rev. 2007, 28, 603-624. [CrossRef]

11. Walser, M.; Samà, M.T.; Wickelgren, R.; Aberg, M.; Bohlooly, Y.M.; Olsson, B.; Törnell, J.; Isgaard, J.; Aberg, N.D. Local overexpression of GH and GH/IGF1 effects in the adult mouse hippocampus. J. Endocrinol. 2012, 215, 257-268. [CrossRef] [PubMed]

12. Rezaei, M.; Zarkesh-Esfahani, S.H. Optimization of production of recombinant human growth hormone in Escherichia coli. J. Res. Med Sci. Off. J. Isfahan Univ. Med Sci. 2012, 17, 681-685.

13. Liang, G.; Cline, G.W.; Macica, C.M. IGF-1 stimulates de novo fatty acid biosynthesis by Schwann cells during myelination. Glia 2007, 55, 632-641. [CrossRef] [PubMed]

14. Cuatrecasas, G.; Kumru, H.; Coves, M.J.; Vidal, J. GH deficiency in patients with spinal cord injury: Efficacy/safety of GH replacement, a pilot study. Endocr. Connect. 2018, 7, 1031-1039. [CrossRef] [PubMed]

15. Barakat-Walter, I.; Kraftsik, R. Stimulating effect of thyroid hormones in peripheral nerve regeneration: Research history and future direction toward clinical therapy. Neural Regen. Res. 2018, 13, 599-608. [CrossRef]

16. Tator, C.H.; van der Jagt, R.H. The effect of exogenous thyroid hormones on functional recovery of the rat after acute spinal cord compression injury. J. Neurosurg 1980, 53, 381-384. [CrossRef]

17. Hwang, D.H.; Park, H.H.; Shin, H.Y.; Cui, Y.; Kim, B.G. Insulin-like Growth Factor-1 Receptor dictates beneficial effects of treadmill training by regulating survival and migration of neural stem cell grafts in the injured spinal cord. Exp. Neurobiol. 2018, 27, 489-507. [CrossRef]

18. Lovejoy, J.C.; Smith, S.R.; Zachwieja, J.J.; Bray, G.A.; Windhauser, M.M.; Wickersham, P.J.; Veldhuis, J.D.; Tulley, R.; de la Bretonne, J.A. Low-dose T(3) improves the bed rest model of simulated weightlessness in men and women. Am. J. Physiol. 1999, 277, E370-E379. [CrossRef]

19. Sun, Y.; Braga-Neto, U.; Dougherty, E.R. A systematic model of the LC-MS proteomics pipeline. BMC Genom. 2012, 13, S2. [CrossRef]

20. Iwamoto, N.; Shimada, T. Recent advances in mass spectrometry-based approaches for proteomics and biologics: Great contribution for developing therapeutic antibodies. Pharmacol. Ther. 2018, 185, 147-154. [CrossRef]

21. Toby, T.K.; Fornelli, L.; Srzentić, K.; DeHart, C.J.; Levitsky, J.; Friedewald, J.; Kelleher, N.L. A comprehensive pipeline for translational top-down proteomics from a single blood draw. Nat. Protoc. 2019, 14, 119-152. [CrossRef]

22. Doucette, A.A.; Nickerson, J.L. Developing front-end devices for improved sample preparation in MS-based proteome analysis. J. Mass Spectrom. 2020, 55, e4494. [CrossRef] [PubMed] 
23. Dardé, V.; Barderas, M.G.; Vivanco, F. Depletion of high-abundance proteins in plasma by immunoaffinity subtraction for two-dimensional difference gel electrophoresis analysis. Methods Mol. Biol. 2007, 357, 351-364. [PubMed]

24. Alonso-Orgaz, S.; Martin-Rojas, T.; Calvo, E.; López, J.A.; Vivanco, F.; Barderas, M.G. Differential protein expression analysis of degenerative aortic stenosis by iTRAQ labeling. Methods Mol. Biol. 2013, 1005, 109-117. [CrossRef]

25. Dardé, V.M.; Barderas, M.G.; Vivanco, F. Multiple reaction monitoring (MRM) of plasma proteins in cardiovascular proteomics. Methods Mol. Biol. 2013, 1000, 191-199. [CrossRef] [PubMed]

26. Bonzon-Kulichenko, E.; Perez-Hernández, D.; Nuñez, E.; Martinez-Acedo, P.; Navarro, P.; Trevisan-Herraz, M.; Ramos Mdel, C.; Sierra, S.; Martinez-Martinez, S.; Ruiz-Meana, M.; et al. A robust method for quantitative high-throughput analysis of proteomes by $18 \mathrm{O}$ labeling. Mol. Cell Proteom. 2011, 10, M110.003335. [CrossRef]

27. Martinez-Bartolome, S.; Navarro, P.; Martin-Maroto, F.; Lopez-Ferrer, D.; Ramos-Fernandez, A.; Villar, M.; Garcia-Ruiz, J.P.; Vazquez, J. Properties of average score distributions of SEQUEST. Mol. Cell Proteom. 2008, 7, 1135-1145. [CrossRef]

28. Navarro, P.; Vazquez, J. A refined method to calculate false discovery rates for peptide identification using decoy databases. J. Proteome Res. 2009, 8, 1792-1796. [CrossRef]

29. Navarro, P.; Trevisan-Herraz, M.; Bonzon-Kulichenko, E.; Nuñez, E.; Martinez-Acedo, P.; Perez-Hernandez, D.; Jorge, I.; Mesa, R.; Calvo, E.; Carrascal, M.; et al. General statistical framework for quantitative proteomics by stable isotope labeling. J. Proteome Res. 2014, 13, 1234-1247. [CrossRef]

30. Bradford, M. A rapid and sensitive method for the quantitation of microgram quantities of protein utilizing the principle of protein-dye binding. Anal. Biochem. 1976, 72, 248-254. [CrossRef]

31. Martín-Rojas, T.; Gil-Dones, F.; Lopez-Almodovar, L.F.; Padial, L.R.; Vivanco, F.; Barderas, M.G. Proteomic profile of human aortic stenosis: Insights into the degenerative process. J. Proteome Res. 2012, 11, 1537-1550. [CrossRef] [PubMed]

32. Shevchenko, A.; Wilm, M.; Vorm, O.; Mann, M. Mass spectrometric sequencing of proteins silver-stained polyacrylamide gels. Anal. Chem. 1996, 68, 850-858. [CrossRef] [PubMed]

33. Perkins, D.N.; Pappin, D.J.C.; Creasy, D.M.; Cottrell, J.S. Probability-based protein identification by searching sequence databases using mass spectrometry data. Electrophoresis 1999, 20, 3551-3567. [CrossRef]

34. Mourino-Alvarez, L.; Baldan-Martin, M.; Sastre-Oliva, T.; Martin-Lorenzo, M.; Maroto, A.S.; Corbacho-Alonso, N.; Rincon, R.; Martin-Rojas, T.; Lopez-Almodovar, L.F.; Alvarez-Llamas, G.; et al. A comprehensive study of calcific aortic stenosis: From rabbit to human samples. Dis. Models Mech. 2018, 11, dmm033423. [CrossRef] [PubMed]

35. Martin-Rojas, T.; Mourino-Alvarez, L.; Gil-Dones, F.; de la Cuesta, F.; Rosello-Lleti, E.; Laborde, C.M.; Rivera, M.; Lopez-Almodovar, L.F.; Lopez, J.A.; Akerstrom, F.; et al. A clinical perspective on the utility of alpha 1 antichymotrypsin for the early diagnosis of calcific aortic stenosis. Clin. Proteom. 2017, 14, 12. [CrossRef] [PubMed]

36. Baldan-Martin, M.; Mourino-Alvarez, L.; Gonzalez-Calero, L.; Moreno-Luna, R.; Sastre-Oliva, T.; Ruiz-Hurtado, G.; Segura, J.; Lopez, J.A.; Vazquez, J.; Vivanco, F.; et al. Plasma molecular signatures in hypertensive patients with renin-angiotensin system suppression: New predictors of renal damage and de novo albuminuria indicators. Hypertension 2016, 68, 157-166. [CrossRef]

37. Lindsey, M.L.; Mayr, M.; Gomes, A.V.; Delles, C.; Arrell, D.K.; Murphy, A.M.; Lange, R.A.; Costello, C.E.; Jin, Y.F.; Laskowitz, D.T.; et al. Transformative impact of proteomics on cardiovascular health and disease: A scientific statement from the American Heart Association. Circulation 2015, 132, 852-872. [CrossRef]

38. Li, S.Y.; Li, Z.X.; He, Z.G.; Wang, Q.; Li, Y.J.; Yang, Q.; Wu, D.Z.; Zeng, H.L.; Xiang, H.B. Quantitative proteomics reveal the alterations in the spinal cord after myocardial ischemia-reperfusion injury in rats. Int. J. Mol. Med. 2019, 44, 1877-1887. [CrossRef]

39. Sarkis, G.A.; Mangaonkar, M.D.; Moghieb, A.; Lelling, B.; Guertin, M.; Yadikar, H.; Yang, Z.; Kobeissy, F.; Wang, K.K. The Application of proteomics to traumatic brain and spinal cord injuries. Curr. Neurol. Neurosci. Rep. 2017, 17, 23. [CrossRef]

40. Kasperska-Zajac, A.; Grzanka, A.; Machura, E.; Misiolek, M.; Mazur, B.; Jochem, J. Increased serum complement $\mathrm{C} 3$ and $\mathrm{C} 4$ concentrations and their relation to severity of chronic spontaneous urticaria and CRP concentration. J. Inflamm. 2013, 10, 22. [CrossRef] 
41. Carpanini, S.M.; Torvell, M.; Morgan, B.P. Therapeutic inhibition of the complement system in diseases of the central nervous system. Front. Immunol. 2019, 10, 362. [CrossRef] [PubMed]

42. Barthel, D.; Schindler, S.; Zipfel, P.F. Plasminogen is a complement inhibitor. J. Biol. Chem. 2012, 287, 18831-18842. [CrossRef] [PubMed]

43. Amara, U.; Flierl, M.A.; Rittirsch, D.; Klos, A.; Chen, H.; Acker, B.; Brückner, U.B.; Nilsson, B.; Gebhard, F.; Lambris, J.D.; et al. Molecular intercommunication between the complement and coagulation systems. J. Immunol. 2010, 185, 5628-5636. [CrossRef] [PubMed]

44. Madathil, S.K.; Evans, H.N.; Saatman, K.E. Temporal and regional changes in IGF-1/IGF-1R signaling in the mouse brain after traumatic brain injury. J. Neurotrauma 2010, 27, 95-107. [CrossRef]

45. Kiernan, J.A. Hypotheses concerned with axonal regeneration in the mammalian nervous system. Biol. Rev. Camb. Philos. Soc. 1979, 54, 155-197. [CrossRef]

46. Seeds, N.W.; Akison, L.; Minor, K. Role of plasminogen activator in spinal cord remodeling after spinal cord injury. Respir. Physiol. Neurobiol. 2009, 169, 141-149. [CrossRef]

47. Rubin, M.R.; Bilezikian, J.P. Hypoparathyroidism: Clinical features, skeletal microstructure and parathyroid hormone replacement. Arq. Bras. Endocrinol. Metabol. 2010, 54, 220-226. [CrossRef]

48. Jiang, S.D.; Jiang, L.S.; Dai, L.Y. Mechanisms of osteoporosis in spinal cord injury. Clin. Endocrinol. 2006, 65, 555-565. [CrossRef]

49. Bajwa, N.M.; Kesavan, C.; Mohan, S. Long-term consequences of traumatic brain Injury in bone metabolism. Front. Neurol. 2018, 9, 115. [CrossRef]

50. Andreassen, T.T.; Oxlund, H. Local anabolic effects of growth hormone on intact bone and healing fractures in rats. Calcif. Tissue Int. 2003, 73, 258-264. [CrossRef]

51. Bost, F.; Diarra-Mehrpour, M.; Martin, J.P. Inter-alpha-trypsin inhibitor proteoglycan family-a group of proteins binding and stabilizing the extracellular matrix. Eur. J. Biochem. 1998, 252, 339-346. [CrossRef] [PubMed]

52. Yamaguchi, Y. Lecticans: Organizers of the brain extracellular matrix. Cell Mol. Life Sci. 2000, 57, $276-289$. [CrossRef]

53. Sherman, L.S.; Back, S.A. A 'GAG' reflex prevents repair of the damaged CNS. Trends Neurosci. 2008, 31, 44-52. [CrossRef] [PubMed]

54. Sengupta, M.B.; Mukhopadhyay, D. Possible role of apolipoprotein A1 in healing and cell death after neuronal injury. Front. Biosci. 2016, 8, 460-477. [CrossRef]

55. Benvenga, S.; Robbins, J. Lipoprotein-thyroid hormone interactions. Trends Endocrinol. Metab. 1993, 4, 194-198. [CrossRef]

Publisher's Note: MDPI stays neutral with regard to jurisdictional claims in published maps and institutional affiliations.

(C) 2020 by the authors. Licensee MDPI, Basel, Switzerland. This article is an open access article distributed under the terms and conditions of the Creative Commons Attribution (CC BY) license (http://creativecommons.org/licenses/by/4.0/). 